\title{
Commentary: Despite global warming, frozen has its place
}

\author{
Joseph S. Coselli, MD
}

\footnotetext{
From the Division of Cardiothoracic Surgery, Michael E. DeBakey Department of Surgery, Baylor College of Medicine, Houston, Tex; Department of Cardiovascular Surgery, Texas Heart Institute, Houston, Tex; and CHI St. Luke's Health-Baylor St. Luke's Medical Center, Houston, Tex.

Disclosures: Dr Coselli consults for, receives royalties and a departmental educational grant from, and participates in clinical trials for Terumo Aortic; consults and participates in clinical trials for Medtronic, Inc, and W. L. Gore \& Associates; and serves as a coinvestigator for CytoSorbents. Dr Coselli's work is partially supported by the Cullen Foundation in the context of his endowed chair. There was no direct support for this article.

Received for publication April 12, 2019; accepted for publication April 13, 2019; available ahead of print May 31, 2019.

Address for reprints: Joseph S. Coselli, MD, One Baylor Plaza, BCM 390, Houston, TX 77030 (E-mail: jcoselli@ bcm.edu).

J Thorac Cardiovasc Surg 2020;159:1212-3

$0022-5223 / \$ 36.00$

Copyright $(c) 2019$ by The American Association for Thoracic Surgery

https://doi.org/10.1016/j.jtcvs.2019.04.049
}

Despite the evolution of aortic arch repair during the last decade, it remains a complex endeavor. ${ }^{1-3}$ Part of the complexity is that disease affecting the aortic arch is rarely isolated and typically incorporates nearby sections of the proximal aorta (ie, aortic root and ascending aorta) or distal aorta (ie, descending thoracic or thoracoabdominal aorta). Traditionally, when the transverse aortic arch is part of extensive aortic pathology (such as in mega-aortic syndromes), a staged approach to repair is undertaken that commonly first replaces the aortic arch and varying portions of the proximal aorta through a median sternotomy and then, after a variable time period that risks between-interval death, replaces the descending thoracic or thoracoabdominal aorta through a thoracotomy or thoracoabdominal incision. ${ }^{4,5}$ Frozen elephant trunk (FET) approaches are used to facilitate a 1-step repair-here, the proximal aorta and a portion of the distal aorta are simultaneously treated.

In this issue of the Journal, Leone and colleagues ${ }^{7}$ present early and midterm results of 437 patients who underwent total arch replacement with FET extension at 2 European centers. The FET prostheses used were the Chavan-Haverich (custom-made; Curative $\mathrm{GmbH}$, Dresden, Germany), the E-vita Open (Jotec, GmbH, Hechingen, Germany), and the Thoraflex Hybrid (Terumo Aortic, Inchinnan, United Kingdom). The main indications for repair were thoracic aortic aneurysm, chronic aortic dissection, and acute aortic dissection. In patients with extensive aneurysmal disease of the thoracic aorta, Leone and colleagues ${ }^{7}$ used the FET approach for single-stage repair, especially if further endovascular repair of the distal aorta was expected-86 patients $(23 \%)$ required an additional procedure. In patients with chronic aortic dissection, the FET technique was used in cases of dilatation of the false lumen as well as to facilitate subsequent endovascular repair by establishing a secure proximal landing zone. Patients with acute type A aortic dissection were treated with FET when the entry tear was located in the distal

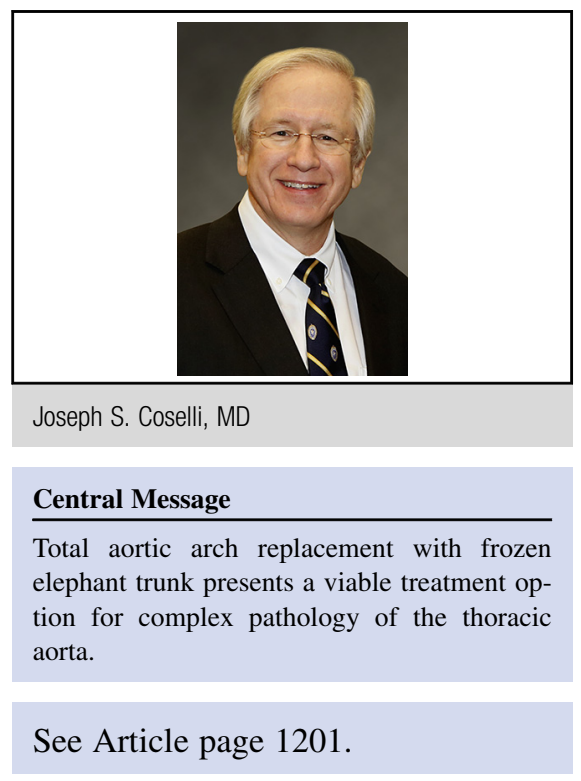

arch or proximal descending aorta, in cases of retrograde aortic dissection, and in instances of true-lumen compression in the descending thoracic aorta (eg, malperfusion). The FET technique was also used in selected cases of complicated acute type B dissection.

In this case series, there were similarities in operative strategy between these European centers. For example, all patients who underwent elective FET procedures received cerebrospinal fluid drainage as part of the operative technique. The use of cerebrospinal fluid drainage is not explicitly endorsed by the European position paper ${ }^{6}$; however, it may help reduce the rate of postoperative paraplegia, which is a well-established risk of FET approaches to aortic arch repair. ${ }^{8-10}$

Leone and colleagues ${ }^{7}$ also described in detail the difference in operative strategies between the European centers of interest, Bologna University and Hannover medical school. For instance, Bologna University provided antegrade cerebral perfusion by using a variety of cannulation sites (such as the right axillary, femoral, innominate, or right carotid arteries) as well as direct cannulation of the ascending aorta, whereas Hannover Medical School commonly provided bilateral antegrade cerebral perfusion using the left carotid and innominate arteries. Further insight into whether these differences yielded differences in outcomes between the centers after total arch replacement with FET procedures would have been of service to the reader of the article of Leone and colleagues ${ }^{7}$; however, the combined outcomes presented do provide valuable information 
on the continued adoption of the FET technique. The combined findings of Leone and colleagues ${ }^{7}$ suggest that independent risk factors for mortality in the overall population were prolonged cardiopulmonary bypass time, age, urgent or emergency surgery, and Marfan syndrome. In contemporary aortic arch repair, the FET approach appears useful for a variety of aortic diseases and may provide an option for single-stage repair for many patients.

\section{References}

1. Coselli JS, Green SY. Aortic arch repair today: open repair is best for most arch lesions. J Cardiovasc Surg (Torino). 2015;56:531-46.

2. Hanif H, Dubois L, Ouzounian M, Peterson MD, El-Hamamsy I, Dagenais F, et al; Canadian Thoracic Aortic Collaborative (CTAC) Investigators. Aortic arch reconstructive surgery with conventional techniques vs frozen elephant trunk: a systematic review and meta-analysis. Can J Cardiol. 2018;34: 262-73.

3. Luehr M, Peterss S, Zierer A, Pacini D, Etz CD, Shrestha ML, et al. Aortic events and reoperations after elective arch surgery: incidence, surgical strategies and outcomes. Eur J Cardiothorac Surg. 2018;53:519-24.
4. Borst HG, Walterbusch G, Schaps D. Extensive aortic replacement using "elephant trunk" prosthesis. Thorac Cardiovasc Surg. 1983;31:37-40.

5. LeMaire SA, Carter SA, Coselli JS. The elephant trunk technique for staged repair of complex aneurysms of the entire thoracic aorta. Ann Thorac Surg. 2006;81:1561-9; discussion 1569.

6. Shrestha M, Bachet J, Bavaria J, Carrel TP, De Paulis R, Di Bartolomeo R, et al Current status and recommendations for use of the frozen elephant trunk technique: a position paper by the Vascular Domain of EACTS. Eur J Cardiothorac Surg. 2015;47:759-69.

7. Leone A, Beckmann E, Aandreas M, Di Marco L, Pantaleo A, Reggiani LB, et al. Total aortic arch replacement with frozen elephant trunk technique: results from two European institutes. J Thorac Cardiovasc Surg. 2020;159:1201-11.

8. Di Bartolomeo R, Murana G, Di Marco L, Pantaleo A, Alfonsi J, Leone A, et al. Frozen versus conventional elephant trunk technique: application in clinical practice. Eur J Cardiothorac Surg. 2017;51(Suppl 1):i20-8.

9. Kozlov BN, Panfilov DS, Ponomarenko IV, Miroshnichenko AG, Nenakhova AA, Maksimov AI, et al. The risk of spinal cord injury during the frozen elephant trunk procedure in acute aortic dissection. Interact Cardiovasc Thorac Surg. 2018;26:972-6.

10. Shrestha M, Kaufeld T, Beckmann E, Fleissner F, Umminger J, Abd Alhadi F, et al. Total aortic arch replacement with a novel 4-branched frozen elephant trunk prosthesis: single-center results of the first 100 patients. J Thorac Cardiovasc Surg. 2016;152:148-59.e1. 